\title{
Improvement in Supply of Construction Material for Construction Industry in Satara City - By Applying Supply Chain Management Tool
}

\author{
Satyajeet D. khutale ${ }^{1}$, Dr.Mrs. Shusma S. Kulkarni ${ }^{2}$ \\ 1Student of M.E.Civil-Construction and Management, 2Director \\ Rajarambapu Institute of Technology, Rajaramnagar, Islampur,
}

\begin{abstract}
Supply chain management (SCM) is a concept that has flourished in manufacturing, originating from Just-In-Time (JIT) production and logistics. Today, SCM represents an autonomous managerial concept, although still largely dominated by logistics. Previous initiatives to advance the construction supply chain have been somewhat partial. The generic methodology offered by SCM contributes to better understanding and resolution of basic problems in construction supply chains, and gives directions for construction supply chain development. The practical solutions offered by SCM, however, have to be developed in construction practice itself, taking into account the specific characteristics and local conditions of construction supply chains. Construction supply chain management's potential for contributing to profitability. Construction supply chain has gained significance because of the increasing number of potential complex private and public sector construction projects. In the construction process costly delays in materials, equipments, and services erode profits. Construction supply chain management through the integration and coordination of materials, information, and money flows between the various project partners resolves delays and offers a new means of increasing profitability. CSCM's emphasis on information sharing and communications fosters cooperation and collaboration among supply chain members. Project management and execution are the final tests of how well the supply chain is working. Tracking progress in the field ensures that a project will be on-time and underbudget and within specifications. Sharing field measurements with all members in accordance with supply chain values is the final predictor of a profitable project.
\end{abstract}

Keywords: CSCM, Construction Supply chain management, JIT (Just in time), profitability, under-budget

\section{Introduction}

The construction industry has become increasingly more complex. There has been significant growth in construction projects in domestic markets and in emerging free market economies throughout the world. Horizontal and vertical construction projects are increasing at an impressive rate. The construction of bridges, highways, schools, housing developments, hospitals, apartment buildings, manufacturing facilities, and levies has led to an explosion in construction knowledge.

The construction industry has been one of the largest in developing countries. While other industries have greatly increased their levels of quality and performance, the majority of construction work is based on traditional techniques with supply drain deficiencies and high defect rates resulting in wasted labour and materials. Many researchers show that $30 \%$ of construction cost is due to inefficiencies, mistakes, delays and poor communication. Especially in developing countries these problems becomes too much costly, where a Significant percentage of material and equipments are imported and time delays may render projects especially susceptible to currency risks and inflationary factors.

As flawed as the individual entities of a construction supply chain may be, they are even more troublesome because a new supply chain or operations component must be developed each time a new project begins. The reality is that the learning that takes place in manufacturing is circumvented in construction by the changes from one project to the next. Construction supply chain management poses an excellent opportunity to at least mitigate some risks by partially integrating some of the lessons learned from the manufacturing sector. A systematic step-by-step approach to operating a value-driven construction company must be adopted Nonetheless, there is mounting evidence of improvements in project performance through taking a supply chain perspective.

Therefore, to be competitive in global economy, there is a need for industry government co-operation to increase the focus on research and development to promote the new culture like supply chain management.

\section{Present need of Supply Chain Management:}

Supply chain management (SCM) that is driven by information technology (IT) is recommended for the construction industry. The construction supply chain management (CSCM) concept has the potential, 
through information, and communication technologies, to overcome some of the fragmentation problems. When the manufacturing definition of SCM is extrapolated to construction, CSCM is defined as the strategic management of information flows, activities, tasks, and processes, involving various networks of independent organizations and linkages (upstream and downstream) which produce value that is delivered to the owner in the form of a finished project.

The upstream activities within CSCM from the perspective of a prime contractor involve the project owner and engineering/design teams as they engage in preparing for the construction process. The downstream activities, which include material suppliers and subcontractors who interact with the prime contractor to carry out the task of building the project, require substantial coordination among project partners. To marry and then manage the downstream and upstream elements of the supply chain, the prime contractor must develop an enabling structure and an efficient communication system for effective relationship management as part of the overall project management. CSCM can easily lead to a natural evolution toward productive relationships throughout the construction process. The considerable documentation, contracts, change orders, purchase orders, specifications, and so on generated both upstream and downstream during the life cycle of a construction project is another reason why the need for CSCM is significant.

When integrated with continuous improvement, CSCM can successfully address major problems of the construction industry and its project owners. CSCM can systematically reduce sources of uncertainty through the active cooperation of all entities in the supply chain in four functional areas: preconstruction design and contractor selection, construction, information management, and risk management.

\section{Background of Supply Chain Management:}

Supply chain management (SCM) is a concept originating from the supply system by which Toyota was seen to coordinate its supplies, and manage its suppliers (Womack et al. 1990). In terms of lean production, SCM is closely related to lean supply (Lamming 1996). The basic concept of SCM includes tools like Just-InTime delivery (JIT) and logistics Management. The current concept of SCM is somewhat broader but still largely dominated by logistics. Until now, in construction, initiatives belonging to the domain of SCM have been rather Partial covering a subset of issues (e.g., transportation costs) in a limited part of the construction supply chain (e.g., the construction site). In most cases, the issues are regarded from a main contractor's point of view (e.g., Asplund and Danielson 1991, Wegelius- Lehtonen et al. 1996). Statistical figures show that main contractors are purchasing more labour and material than previously. For instance, in 1994, in Dutch construction industry (i.e. residential, commercial and industrial building), the main contractors' share in the total national turnover had decreased to $24 \%$ (Scholman 1997). Thus, suppliers and subcontractors represented about $5 \%$ of turnover. Currently, this is expected to be more. As a consequence, main contractors become more and more reliant on other actors in the construction supply chain (e.g., suppliers and subcontractors). Therefore, they need to revise their supply strategies and trading relations with subcontractors and suppliers. SCM is a concept that has originated and flourished in the manufacturing industry. The first signs of SCM were perceptible in the JIT delivery system as part of the Toyota Production System (Shingo 1988). This system aimed to regulate supplies to the Toyota motor factory just in the right - small - amount, just on the right time. The main goal was to decrease inventory drastically, and to regulate the suppliers' interaction with the production line more effectively. After its emergence in the Japanese automotive industry as part of a production system, the conceptual evolution of SCM has resulted in an autonomous status of the concept in industrial management theory, and a distinct subject of scientific research, as discussed in literature on SCM (e.g., Bechtel and Yayaram 1997, Cooper et al. 1997). Along with original SCM approaches, other management concepts (e.g., value chain, extended enterprise) have been influencing the conceptual evolution towards the present understanding of SCM. In a way, the concept of SCM represents a logical continuation of previous management developments (Van der Veen and Robben 1997). Although largely dominated by logistics, the contemporary concept of SCM encompasses more than just logistics (Cooper et al. 1997). Actually, SCM is combining particular features from concepts including Total Quality Management (TQM), Business Process Redesign (BPR) and JIT (Van der Veen and Robben 1997).

\section{What is supply chain? What is supply chain management?}

The term "supply chain" refers to a series of interdependent steps of activities or processes (sometimes sequential and sometimes overlapping) as well as flows between them, supported by infrastructure (people, equipment, buildings, soft ware, etc.) [e.g., Simchi-Levietal. 2007; Fine and Whitney 1996]. These flows express real or forecast customer demand going in one direction, and supply going in the other direction in order to fulfil that demand. Figure 1.1 outlines the general directions of these flows. Demand and supply flow in opposite directions but may follow different routes (they are not necessarily one-on-one opposites of each other). Information flows both ways. Products and services also may flow both ways (e.g., a fabricator may ship products to a galvanizer and then incorporate returned products into larger assemblies). Accordingly, the term 
supply "network" might be a better characterization of this system than supply "chain" is, but the latter term is used more commonly and will thus be used throughout this chapter. Supply chain management (SCM) refers to managing the flows of physical products and services, information, and money between the activities or process steps that companies perform, while aiming for customer service as the goal (i.e., get the right product to the right place at the right time for the right cost). Defined in this way, SCM applies to the delivery of capital projects (so-called "project supply chains") as it does to the delivery of products or services in other industries1 (supply chains that deliver products are sometimes referred to as "product supply chains").
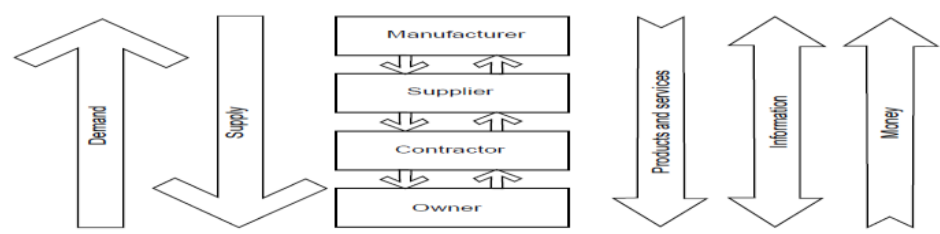

Figure 1.1 shows examples of supply \& demand with flow of product/services, information \& money in supply chain (Philip kamensky, Glenn barad, iris D. Tommenlion)

Supply chain management is the combination of art and science that goes into improving the way your company finds the raw components it needs to make a product or service, manufactures that product or service and delivers it to customers.

"Supply chain management is a set of approaches used to efficiently integrate suppliers, manufacturers, warehouses, and customers so that merchandise is produced and distributed at the right quantities, to the right locations, and at the right time in order to minimize system wide costs while satisfying service-level requirements."

Supply chain management involves the strategic and process coordination of subcontractors, material suppliers, and information within the supply chain to deliver satisfaction to the ultimate project owner. While each business entity in the supply chain has been traditionally driven by self-profitability, the notion of supply chain management involves optimization of synergistic relationships between supply chain members to ultimately satisfy the project owner. The concept evolves from controlling the supply chain as a single process rather than as a sum of independent transactional relationships. The expected end result is a mutually beneficial, win-win partnership that creates a synergistic supply chain in which the entire chain is more effective than the sum of its individual parts. Ideally, supply chain management represents a win-win, utopian goal of circular benefits. See Fig 1.2. Each company in the supply chain obtains its own profitability and success by creating customer Value in terms of a functional, high-quality project at an acceptable price. Each organization within the supply chain can reduce its own costs and increase its project performance through supply chain management, thereby enabling the supply chain to deliver value to the project owner. The satisfied project owner in turn rewards the supply chain with loyal contracting power, allowing profitability to be transferred back down throughout the supply chain. This in turn fosters further supply chain integration and responsiveness, causing the cycle to repeat. A prime contractor may be able to position a firm as a market leader through exploitation of best practice operations, but the nature of the linked firms in the supply chain necessitates that subcontractors and material suppliers must be part of this strategy. The prime contractor cannot become an industry leader without supply chain support, and, thus, supply chain management is a prerequisite for developing a competitive advantage for successful construction operations. As an example, the Japanese auto manufacturers brought their cutting edge production and supply chain processes to the United States. The subsequent

Intense competition forced Chrysler and General Motors to bankruptcy. At a minimum, competitive auto manufacturers must focus on operations excellence throughout the supply chain. The next generation of auto manufacturers must therefore develop a new orientation

To the supply chain, transferring design, cost reduction and quality issues to their suppliers.

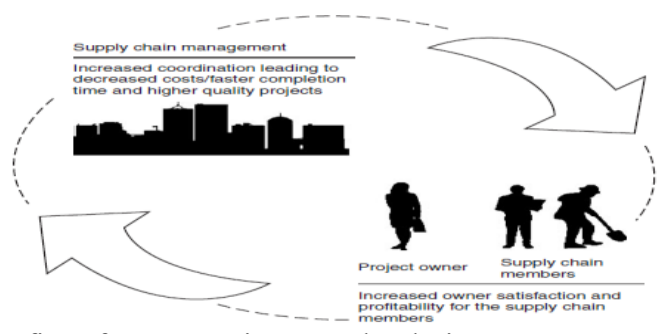

Figure 1.2 shows circular benefits of construction supply chain management (W.C. Benton, Jr. \& Linda F. Mchenry) 


\section{Why Supply Chain Management:}

Manufacturing strategies have run their courses Effective Supply Chain Managment. is the next logical step towards increased profits and market share. Construction supply chain management through the integration and coordination of materials, information, and money flows between the various project partners resolves delays and offers a new means of increasing profitability. CSCM's emphasis on information sharing and communications fosters cooperation and collaboration among supply chain members. Contract arrangements that promote core values across all levels of the supply chain depart from traditional practices by advancing successful project outcomes instead of individual firm's successes. Project management and execution are the final tests of how well the supply chain is working. Tracking progress in the field ensures that a project will be on-time and under budget and within specifications. Sharing field measurements with all members in accordance with supply chain values is the final predictor of a profitable project.

\section{Construction Supply Chain Management:}

The construction supply chain is an operational and strategic cycle that includes labour, materials, equipment, subcontracting, and a finished project. Technology, safety, and communications are the three elements that connect all of the components of the chain. The construction supply chain has even more significance because of the potential for participation in many complex private and public sector construction projects. The concept of the construction supply chain implicitly takes a strategic look at profitability. In the short run, contractors may be able to survive with losses; however, in the long run, every construction business must show a profit in order to be considered a going concern. Profit or net income is a component of retained earnings on the balance sheet. Retained earnings pay for the future

By enabling contractors to buy new equipment and hire, train, and develop more employees. Successful construction organizations must focus on the question: "What is meant by profitability?" Any one of the five approaches listed below or combination of them will

Increase profits:

- Increase contract revenues through niche marketing.

- Decrease the total cost of construction.

- Decrease overhead.

- Increase other income and decrease expenses.

- Decrease delays in deliveries of materials, equipment, and services to the project site.

Increasing contract revenues alone is not enough to ensure profits. Project owners must be targeted through niche marketing. What category of work should a construction organization consider based on its expertise and skill sets? Is subcontracting an effective approach for marketing construction services? The measurement criteria for a good niche are the profitability and predictability of the project outcome. In other words, if a company can consistently deliver a specific type of high-quality project ahead of schedule and under budget, this may be an optimum project for the firm. Once a firm makes a commitment to a particular item of work and type of project owner, finishing ahead of schedule is critical to increasing the revenues. The old adage in the construction industry is "Get in and get out."

One way to decrease the total cost of construction is to increase productivity through better work methods and effective supervision. Two conduits of the construction supply chain, technology and safety, are also critical to decreasing the cost of construction. By implementing technology in the field and home office operations, firms can reduce the time it takes to perform certain routine administrative tasks. A safe workplace means no fines, fewer workers' compensation claims or other litigation, and a good reputation in the community. Another effective means for increasing profitability is reducing overhead. The home office must be the appropriate size so that it supports the firm's operations; some contractors have too many employees working in the home office. Another approach to increasing profitability is to increase other income and decrease related expenses. Efficient billing systems that turn receivables quickly improve cash flow and minimize interest payments for borrowed funds.

The final means of increasing profitability is by implementing supply chain management concepts in order to decrease delays in delivery of materials, equipment, and services to the project site. As shown in Fig 1.3. Construction is unlike any other industry. The industry is composed of many fragmented self-protected entrepreneurs with paranoid attitudes. The industry actually promotes an adversarial culture based on competition and very little information sharing. Unlike the manufacturing sector, each project is based on a uniformed distribution for that specific project with little motivation for continuous learning. In contrast, in the manufacturing sector, units of production are based on a continuous exponential distribution. In spite of the fact that construction is a rich industry - approximately $\$ 3$ trillion was spent in 2007 - it has historically been a slow- to no-learning industry. However, the days of slow learning construction firms are coming to an end. More and more firms in the construction industry are adopting the lessons learned from the manufacturing sector. Progressive firms are now implementing six sigma and lean management initiatives to drive efficiencies 
for their project operations. This transition has generated the construction supply chain management revolution. (W.C. Benton, Jr.\& Linda F. McHenry)

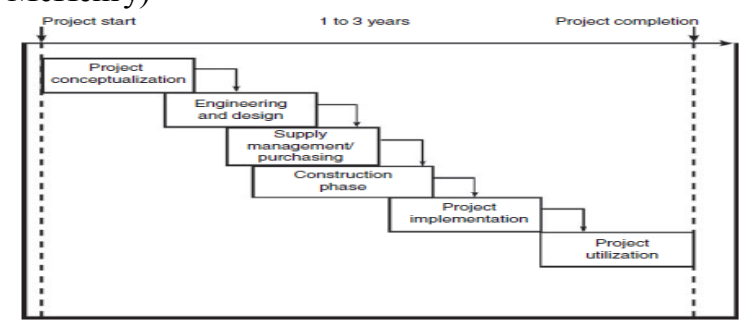

Figure 1.3 shows typical industrial construction project life cycle (W.C. Benton, Jr. \& Linda F. Mchenry)

\section{Barriers to Supply Chain Management:}

Supply chain management offers promise for the construction industry. Intense implementation challenges, however, often prevent effective exploitation of supply chain management benefits and prove detrimental to any planned operational efficiency advantage. One barrier, the individualistic and adversarial history of the industry makes it difficult to create involved cooperative relationships with other constructionrelated entities. Specifically, supply chain management necessitates sharing of traditionally proprietary information, strategy, planning and goals, and most construction firms do not feel comfortable exposing such elements to other firms, fearing loss of control. Furthermore, interfirm collaboration requires each participating firm to create a high level of awareness of both themselves and their partners, and such cognition is often difficult to accomplish effectively. Yet another problem involves the inability of chain members to focus on one mutual goal of the supply chain rather than individual performance. Other significant barriers to the execution of supply chain management include a lack of understanding of the project owner (who is the true customer and what do they really want?), communication gaps (in what ways is it difficult for separated members to communicate?), a lack of understanding of the true supply chain (what firms are in the chain?), the enormous size of many supply chains (is it difficult to coordinate many independent firms?), a lack of effective leadership (who is the best leader?), egocentrism (is pride creating a myopic strategy?), and finally, a deficiency of mutuality (are profits and rewards shared equally?). On the basis of the above barriers to supply chain management, development of an integrated supply chain remains an extremely difficult task. It represents a new way of doing business, and most construction firms are not prepared or even necessarily willing to effectively integrate the chain. Though it is perhaps a distant goal, the concept of supply chain management remains a critical factor for the long-term success of construction firms. While complete supply chain management may be out of reach for most construction firms, application of its concepts will improve their competitive advantage. Furthermore, as the supply chain best practice firms are able to improve project quality, completion times, and work methods while decreasing costs, the demanding project owner will continue to demand more. As a result, the efficient construction supply chains will prosper, and the traditional, adversarial supply chains will not survive. For this reason, construction supply chain management remains a critical element for positioning operational efficiency as a source of competitive advantage, and serves as a desirable goal for leadership in the construction industry. (W.C. Benton, Jr. \& Linda F. McHenry)

- Failure to share project information

- Fear of loss of control

- Lack of self awareness

- Lack of partner awareness

- Enormity of the project complexity

- Inability to recognize project goals

- Lack of understanding project owner

- Lack of understanding of supply chain

- Myopic thinking, myopic strategies, deficiency of mutuality

\section{Traditional Construction Supply Chain:}

Firms must take bold steps to break down intrafirm barriers to both smooth uncertainty and enhance control of the supply chain activities. See Fig 1.4. The evolution of intrafirm functional integration has occurred for most progressive construction firms over the last few decades, and the current push is toward external integration with subcontractors, material suppliers, and project owners. Supply chain partnerships bridge the barrier between prime contractors, subcontractors, materials suppliers, and project owners. Historically, contractors have formulated operations strategy around adversarial downstream relationships. This approach encourages competition which the prime contractors can exploit to shop for lower costs. Such a strategy 
enhances ultimate prime contractor bargaining power. This is clearly an unsustainable strategy. The most productive subcontractors and material suppliers will join progressive supply chain networks.

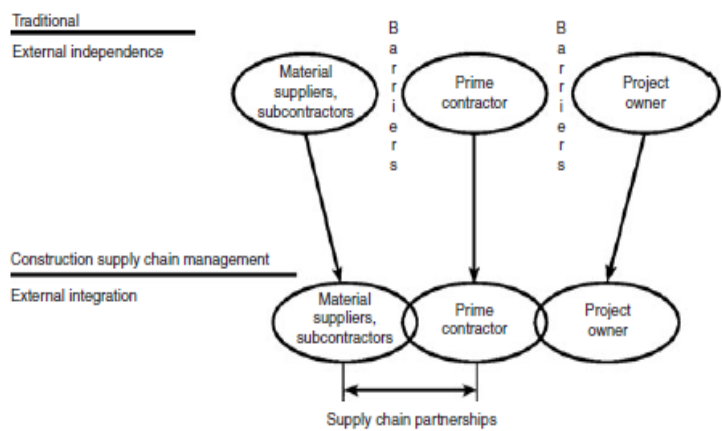

Figure 1.4 shows the evolution from traditional to construction supply chain management integration (W.C. Benton, Jr. \& Linda F. Mchenry)

A Harvard Business School study concluded that a key driver in the decline of U.S. competitiveness in the international marketplace has originated from investing less in intangible benefits such as relationship building.4 According to McNeil, it is impossible to operate as a discrete entity. But, while virtually no firm has completely discrete engagements, conventional Western and American business practices have been more oriented toward discrete than relational strategies. 5 Traditionally, U.S. firms have based their drive for success on autonomy and have viewed competition as a Darwinistic keeper of American superiority. Long-run U.S. firm planning has been independent, and considerable efforts are taken to ensure privacy of company information. Over recent decades, however, American firms within the supply chain have begun to realize the advantages enjoyed from sharing technology, information, and planning with other firms and even competitors. Many modernistic business thinkers will claim that a more open and relational attitude is not only advantageous, but is also actually essential and inevitable in maintaining a competitive advantage. The idea of relationalism between firms seeks to move Away from the concept of discrete transactions, breaking down traditional intrafirm barriers. Firms unite to share information and planning efforts, thus reducing uncertainty as well as increasing control. In the end, supply chain partners reap the benefits of the joint effort. Modern construction improvements such as Lean management methods require the tighter control generated by the construction supply chain partnership. Strategic construction supply alliances, however, extend well beyond this notion to an even more relational level of exchange in which partners create an intensive, interdependent relationship from which both can mutually benefit. Strategic construction supply partnerships emphasize a direct, long-term association, encouraging mutual planning and problem-solving efforts.

\section{Modern Supply Chain Management Approach:}

In Collaborate Planning Forecasting Replenishment (CPFR) Age (R.V. Altekar 2005), all the organized players are seen as one entity i.e. manufacturing organization closely operates with all the trading partners including customers at one side and suppliers at other side. Typically, this approach integrates all of its internal supply chain as well as external supply chain operations to deliver value to the final customers. Fig no.1.8

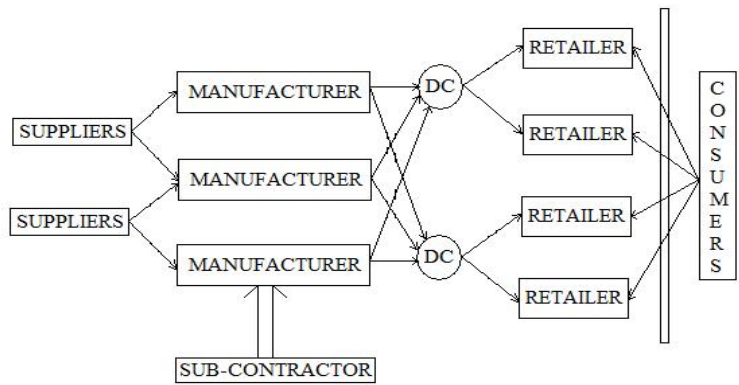

Figure 1.8 shows Modern approach (CPFR Age) (W.C. Benton, Jr. \& Linda F. Mchenry)

In the Global E-biz Age (as shown in fig. 1.9) (R.V. Altekar 2005), consumers can directly talk with manufacturing company that is also a patent holder perhaps no material physically flows to or from this patent holder. It means that the manufacturing operations will be outsourced to the $4^{\text {th }}$ level and logistics services supplier's job is to lift required material from the point of supply to the pt. of demand, and ultimately deliver the product to consumer. 


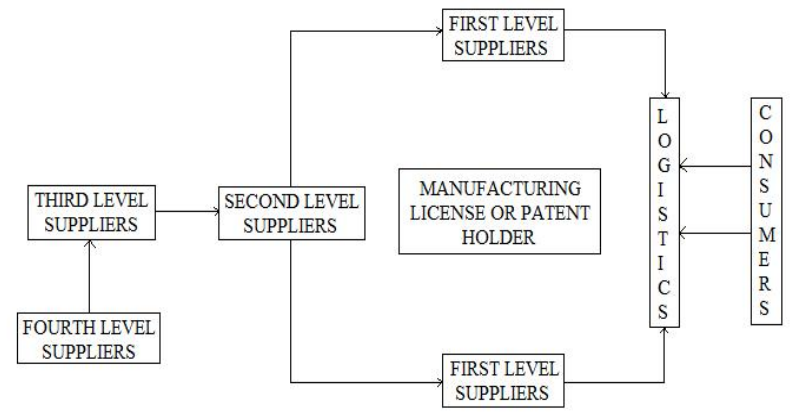

Figure 1.9 shows Supply Chain Management approach in E-Biz Age (W.C. Benton, Jr. \& Linda F. Mchenry)

\section{Conclusion:}

Supply Chain Management identifies the relationship between companies and their suppliers. It can be applied to the construction industry to increase efficiency in deliver and quality of materials. Wastage is reduced because inventories can be reduced, with reduced inventories, problems arising from poor storage and handling conditions may be avoided. Especially with increased subcontracting, it is even more important to ensure a positive relationship between main contractors and subcontractors. The principal-agent theory illustrates the importance of good relationships and control of the main contractors over subcontractors. Control of the subcontractors' behaviour so that they implement waste minimization methods would prove to be beneficial as waste generation basically results from their poor workmanship and attitude.

\section{References}

[1]. Altekar R.V. (2005), “A Textbook of Supply Chain Management: Concepts and Cases”, Prentice Hall India Publications, New Delhi, India, (1-11, 43-45, 96-104, 174-182, 190-192, 199-200, 396-398)

[2]. Fredrik Olsson (2000), "Supply Chain Management in the Construction Industry - Opportunity or utopia" (Lund University ,Department of Design Sciences, Logistics,Lund,SWEDEN)

[3]. Handbook on Construction Supply Chain Management. ( William J. O Brien, Carlos T. Formoso, Ruben Vrijhoef, Kerry A. London)

[4]. Journals on Project Management and Construction Management

[5]. Text Book of "Environmental Science"

[6]. Construction Supply Chain modelling: a research review \& interdisciplinary reserach agenda (William J. O Brien, Kerry London \& Ruben Vrijhoef)

[7]. Benton, W. C., Purchasing and Supply Management, McGraw-Hill, New York, 2007.

[8]. Harris, L. D., and M. B. Perlberg, 2008, "The Advantage of the Consensus DOCS," presented at Winds of Change, "The Consensus DOCS," American Bar Association Forum on the Construction Industry,

[9]. MacBeth, D. K., and N. Ferguson, 1994. Partnership Sourcing: An Integrated Supply Chain Management Approach, Pitman Publishing, London,

[10]. J.L. Gattorna and D.W. Walters (2006), "A Textbook of Managing the Supply Chain: A Strategic Perspective", Palgrave Publications, New York, USA, (1-17, 122-136, 165-171, 189-195)

[11]. Ruben Vrijhoef and Lauri Koskela (1999), "Roles of Supply Chain Management in Construction”, Proceedings IGLC-7, University of California, Berkeley, CA, USA, (134-146)

[12]. MacBeth, D. K., and N. Ferguson, Partnership Sourcing: An Integrated Supply Chain Management Approach, Pitman Publishing, London, 1994.

[13]. Handbook on Construction Supply Chain Management. ( William J. O Brien, Carlos T. Formoso, Ruben Vrijhoef, Kerry A. London)

[14]. Construction Supply Chain modelling: a research review \& interdisciplinary reserach agenda (William J. O Brien, Kerry London \& Ruben Vrijhoef)

[15]. Eric Zimmer, Ossama Salem, Ashraf Genaidy and Richard Shell (2008), "Case Study: Lean Supply Chain Management in Construction Process", Proceedings IGLC-16, Manchester, UK, (381-387)

[16]. Iris D. Tommelein and Markus Weissunberger (1999), "More Just In Time: Location of Buffers in Structural Steel Supply and Construction Processes", Proceedings IGLC-7, University of California, Berkeley, CA, USA, (109-120)

[17]. Kornelius, L., and Wamelink, J.W.F. (1998).’The virtual corporation: learning from construction.” Supply Chain Management 3 (4), 193-202. 